\title{
JOSEPH CONRAD No BRASIL
}

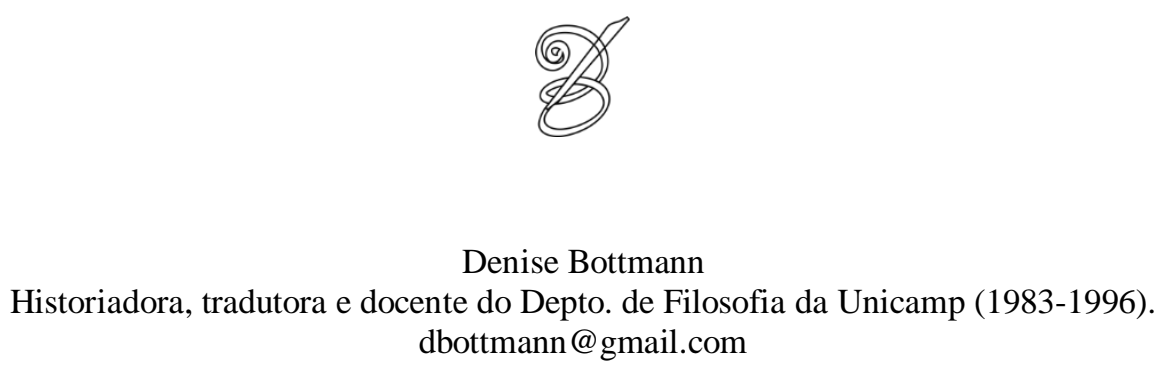

Resumo: Este artigo apresenta um levantamento das traduções da obra de Joseph Conrad publicadas no Brasil, desde 1934 a 2012.

Palavras-chave: Joseph Conrad, traduções brasileiras.

Abstract: This short essay lists Joseph Conrad's writings translated and published in Brazil, since 1934 through 2012.

Keywords: Joseph Conrad, Brazilian translations.

obra de Joseph Conrad (1857-1924) é até razoavelmente traduzida no Brasil:

A talvez cerca de um terço dela. Apresento a seguir um levantamento das traduções outra, praticamente todas elas tiveram maior ou menor número de reedições na editora de referência e, em alguns casos, o licenciamento para outras editoras.

Foi por iniciativa da Livraria do Globo que Joseph Conrad chegou ao país, numa sucessão relativamente rápida. Em oito anos, saem pela Globo quatro romances e uma coletânea de contos de Conrad:

- 1934, O agente secreto, em tradução de Pepita Leão;

• 1936, Tufão e outras histórias (com “Tufão”, “Amy Foster”, "Falk” e “Amanhã”), em tradução de Queiroz Lima;

- 1939, Lord Jim, em tradução de Mário Quintana;

- 1940, A flecha de ouro, em tradução de Marques Rebelo;

- 1942, Vitória, em tradução de Leonel Vallandro.

Ainda em 1942, sai "Uma guarda avançada do progresso" na coletânea Contos ingleses, organizada por Jacob Penteado, pela Edigraf. Embora não constem os créditos, tratase da tradução portuguesa de Cabral do Nascimento. 
Em 1944, sai "Juventude", em tradução de Edison Carneiro na coletânea Os ingleses: antigos e modernos, organizada por Rubem Braga e publicada pela Editora Leitura.

Segue-se uma calmaria de vinte anos, até que, em 1964, a Editora Boa Leitura lança Perdição e contos de inquietude, em tradução de Virgínia Lefèvre. Perdição corresponde a Almayer's Folly e os cinco contos (Tales of Unrest) são "Karain, uma lembrança", "Os idiotas", "Um posto avançado de progresso", "A volta" e "A laguna". [Diga-se de passagem que a Boa Leitura havia publicado um Lord Jim em 1960, mas não consegui descobrir se era uma retradução ou um licenciamento da tradução de 1939.]

Passa-se mais algum tempo, até que:

- em c. 1978 sai A linha de sombra: uma confissão, em tradução de Maria Antonia van Acker, pela Hemus;

- $\quad$ em 1978 temos "Por causa dos dólares" (integrante da coletânea Within the Tides), na edição revista e ampliada da antologia Mar de histórias, em tradução de Aurélio Buarque de Hollanda e Paulo Rónai, pela Nova Fronteira;

- em 1982 vem Vitória, em tradução de Marcos Santarrita, pela Francisco Alves;

- no mesmo ano, sai uma nova tradução de Lorde Jim, também por Marcos Santarrita e também pela Francisco Alves;

- no ano seguinte, 1983, sai Nostromo, em tradução de Donaldson Garschagen, pela Record.

Note-se que, nesses cinquenta anos de publicação de Conrad no Brasil, entre 1934 e 1983, não há nem sinal daquela obra que, hoje em dia, é a mais espantosamente traduzida e retraduzida entre nós, Heart of Darkness (com nada menos que 13 traduções/ adaptações diferentes).

É em 1984 que se inicia o surto, provavelmente na esteira do sucesso do filme Apocalypse Now, com três traduções lançadas no mesmo ano:

- Coração das trevas, em tradução de Regina Régis Junqueira, pela Itatiaia;

- O coração da treva, em tradução de Hamilton Trevisan, pela Global;

- $O$ coração das trevas, em tradução de Marcos Santarrita, pela Brasiliense.

A partir daí, a onda conradiana ganha impulso e avança com uma razoável variedade de novos títulos e mais algumas retraduções:

- 1984, Sob os olhos do Ocidente, em tradução de Marcos Santarrita, pela Brasiliense;

- 1985, A força do acaso, ou Chance, em tradução de Francisco da Rocha Filho, pela Marco Zero;

- 1985, O cúmplice secreto, em tradução de Marilene Felinto e Heloísa Prieto, pela Max Limonad; 
- 1985, Tufão \& outras histórias (com "Tufão", “Amy Foster” e "Amanhã”), em tradução de Albino Poli Jr., pela L\&PM;

- 1986, Juventude, em tradução de Flávio Moreira da Costa, pela Marco Zero;

- 1987, Lord Jim, adaptação de Cordélia Dias d'Aguiar, na Coleção Elefante, Ediouro;

- 1991, Nostromo, em tradução de José Paulo Paes, pela Companhia das Letras;

- 1994, Mocidade e O parceiro secreto, em tradução de Maria Ercília Galvão Bueno, pela Imago;

- 1995, O agente secreto: uma história singela, em tradução de Laetitia Vasconcellos, pela Imago;

- 1997, O coração das trevas, em tradução de Albino Poli Jr., pela L\&PM;

- 1999, Espelho do mar, seguido de Um registro pessoal, em tradução de Celso Mauro Paciornik, pela Iluminuras;

- 1999, A loucura do Almayer, em tradução de Julieta Cupertino, pela Revan.

Aqui vale a pena citar rapidamente o caso de Julieta Cupertino: nascida em outubro de 1907 e atualmente com 104 anos de idade, com amorosa dedicação começou a traduzir as obras de Conrad já nonagenária. Ao longo dos anos, a Revan vem publicando esse seu paciente trabalho, e assim é que, na sequência de A loucura do Almayer, que saiu em 1999, temos as seguintes traduções de Cupertino, sempre pela Revan:

- 2000, O fim das forças

- 2001, Juventude: uma narrativa (edição bilíngue)

- 2001, Lord Jim

- 2003, Freya das sete ilhas

- 2004, Dentro das marés

- 2004, Duas histórias (“Karain: uma memória” e "Um posto avançado do progresso")

- 2005, A linha de sombra

- 2007, Amy Foster

- 2008, O duelo

- 2009, Vitória

- 2011, Coração das trevas

Em 2002, entre essa sequência acima listada, a mesma editora publicou também $O$ agente secreto, em tradução de Paulo Cezar Castanheira.

Retomando a ordem cronológica das traduções e retraduções de Conrad no Brasil, e já apresentados os 12 títulos que saíram pela Revan desde 2000, prossegue a onda conradiana, 
agora com predomínio maciço de retraduções, sobretudo de Heart of Darkness, e apenas uma ou outra coisa que ainda estava inédita entre nós:

- 2001, Coração das trevas, em tradução de Juliana L. Freitas, pela Nova Alexandria;

- 2002, O coração das trevas, seguido de O cúmplice secreto, em tradução de Celso Mauro Paciornik, pela Iluminuras;

- 2003, Juventude: uma narrativa, e O parceiro secreto, em tradução de Valéria Medeiros, pela Paz e Terra;

- 2005, "A fera" (integrante da coletânea A Set of Six), em Contos de horror do século XIX, tradução de Laetitia Vasconcellos, pela Companhia das Letras;

- 2005, Coração das trevas, em adaptação de José Vicente Bernardo, pela Nova Alexandria;

- 2007, O coração das trevas, em adaptação de Rodrigo Espinosa Cabral, pela Rideel;

- 2007, O coração das trevas, em tradução de Luciano Alves Meira, pela Martin Claret;

- 2007, "O duelo", em Mestres-de-armas - seis histórias sobre duelos, em tradução de Cláudio Figueiredo, pela Companhia das Letras;

- 2007, Os duelistas, em tradução de André de Godoy Vieira, pela L\&PM;

- 2007, "Um posto avançado do progresso", em Os melhores contos que a história escreveu, em tradução de Maria Luiza X. de A. Borges, pela Nova Fronteira;

266 - 2008, Coração das trevas, seguido de Um posto avançado do progresso, em tradução de Sergio Flaksman, pela Companhia das Letras;

- 2008, No coração das trevas, em tradução de José Roberto O’Shea, pela Hedra;

- 2009, Um anarquista e outros contos ("Um anarquista", "O informante", "Il conde" e "A bruta", extraídos da coletânea A Set of Six), em tradução de Dirceu Villa, pela Hedra;

- 2010, A linha de sombra: uma confissão, em tradução de Guilherme Braga, pela L\&PM;

- 2010, O agente secreto, em tradução de Eduardo Furtado, pela Landmark;

- 2011, O coração das trevas, em tradução de Fábio Cyrino, pela Landmark.

Encontrei menção a um conto de Conrad em Contos de amor e desamor, pela Agir, mas não consegui maiores informações. Entre as ausências incompreensíveis, destacam-se The Nigger of the "Narcissus" e "Gaspar Ruiz", este integrante de A Set of Six, coletânea do autor inexplicavelmente desmembrada entre nós.

Cabe ainda lembrar o lamentável descaminho da Editora Nova Cultural em sua coleção "Obras-Primas", lançando em 2003 um Lord Jim com pretensa tradução atribuída a uma "Carmen Lia Lomônaco", que, em verdade, constituía mera cópia da decana tradução de Mário Quintana. 
Segue-se a tabela dos escritos de Conrad publicados no Brasil, em escala decrescente do número de traduções, em blocos dispostos internamente em ordem cronológica:

\begin{tabular}{|l|l|l|r|}
\hline Heart of Darkness & \multicolumn{2}{l}{ Tradução } & Aditora \\
\hline Coração das trevas & Regina Régis Junqueira & Itatiaia & 1984 \\
\hline O coração da treva & Hamilton Trevisan & Global & 1984 \\
\hline O coração das trevas & Marcos Santarrita & Brasiliense & 1984 \\
\hline O coração das trevas & Albino Poli jr. & L\&PM & 1997 \\
\hline Coração das trevas & Juliana L. Freitas & Nova Alexandria & 2001 \\
\hline O coração das trevas & Celso Mauro Paciornik & Iluminuras & 2002 \\
\hline O coração das trevas & Luciano Alves Meira & Martin Claret & 2007 \\
\hline Coração das trevas & Sergio Flaksman & Cia. das Letras & 2007 \\
\hline No coração das trevas & José Roberto O'Shea & Hedra & 2008 \\
\hline O coração das trevas & Fábio Cyrino & Landmark & 2011 \\
\hline Coração das trevas & Julieta Cupertino & Revan & 2011 \\
\hline Coração das trevas & Adaptação & & \\
\hline O coração das trevas & José Vicente Bernardo & Nova Alexandria & 2005 \\
\hline & Rodrigo Espinosa Cabral & Rideel & 2007 \\
\hline
\end{tabular}

\begin{tabular}{|l|l|l|r|}
\hline Youth & Tradução & Editora & Ano \\
\hline Juventude & Edison Carneiro & Leitura & 1944 \\
\hline Juventude & Flávio Moreira da Costa & Marco Zero & 1986 \\
\hline Mocidade & Maria Ercília Galvão Bueno & Imago & 1994 \\
\hline Juventude: uma narrativa & Julieta Cupertino & Revan & 2001 \\
\hline Juventude: uma narrativa & Valéria Medeiros & Paz e Terra & 2003 \\
\hline
\end{tabular}

\begin{tabular}{|l|l|l|r|}
\hline An Outpost of Progress & Tradução & \multicolumn{2}{|c|}{ Editora } \\
\hline Uma guarda avançada do progresso & Cabral do Nascimento (port.) & Edigraf & 1942 \\
\hline $\begin{array}{l}\text { Um posto avançado } \\
\text { de progresso }\end{array}$ & Virgínia Lefèvre & Boa Leitura & 1964 \\
\hline $\begin{array}{l}\text { Um posto avançado } \\
\text { do progresso }\end{array}$ & Julieta Cupertino & Revan & 2004 \\
\hline $\begin{array}{l}\text { Um posto avançado } \\
\text { do progresso }\end{array}$ & Maria Luiza X. de A. Borges & Nova Fronteira & 2007 \\
\hline $\begin{array}{l}\text { Um posto avançado } \\
\text { do progresso }\end{array}$ & Sergio Flaksman & Cia. das Letras & 2008 \\
\hline
\end{tabular}




\begin{tabular}{|l|l|l|r|}
\hline The Secret Agent & Tradução & Globo & Ano \\
\hline O agente secreto & Pepita Leão & Imago & 1934 \\
\hline O agente secreto & Laetitia Vasconcellos & Revan & 2002 \\
\hline Oagente secreto & Paulo Cezar Castanheira & Landmark & 2010 \\
\hline Oagente secreto & Eduardo Furtado &
\end{tabular}

\begin{tabular}{|l|l|l|r|}
\hline The Secret Sharer & Tradução & Max Limonad & 1985 \\
\hline O cúmplice secreto & $\begin{array}{l}\text { Marilene Felinto } \\
\text { e Heloísa Prieto }\end{array}$ & Imago & 1994 \\
\hline O parceiro secreto & Maria Ercília Galvão Bueno & Iluminuras & 2002 \\
\hline O cúmplice secreto & Celso Mauro Paciornik & Paz e Terra & 2003 \\
\hline O parceiro secreto & Valéria Medeiros & & \\
\hline
\end{tabular}

\begin{tabular}{|c|c|c|c|}
\hline Lord Jim* & Tradução & Editora & \\
\hline Lord Jim & Mário Quintana & Globo & 1939 \\
\hline Lorde Jim & Marcos Santarrita & Francisco Alves & 1982 \\
\hline Lord Jim & $\begin{array}{l}\text { Julieta Cupertino } \\
\text { Adaptação }\end{array}$ & Revan & 2001 \\
\hline Lord Jim & Cordélia Dias d'Aguiar & Ediouro & 1987 \\
\hline
\end{tabular}

*Há um registro não identificado de uma edição pela Boa Leitura, em 1960. Há uma fraude de tradução publicada pela Editora Nova Cultural em 2003, em nome de "Carmen Lia Lomônaco"

\begin{tabular}{|l|l|l|r|}
\hline Victory & \multicolumn{1}{l}{ Tradução } & Editora & \multicolumn{1}{c|}{ Ano } \\
\hline Vitória & Leonel Vallandro & Globo & 1942 \\
\hline Vitória & Marcos Santarrita & Francisco Alves & 1982 \\
\hline Vitória & Julieta Cupertino & Revan & 2009 \\
\hline
\end{tabular}

\begin{tabular}{|l|l|l|r|}
\hline Amy Foster & Tradução & Globo & Ano \\
\hline Amy Foster & Queiroz Lima & L\&PM & 1936 \\
\hline Amy Foster & Albino Poli Jr. & Revan & 2085 \\
\hline Amy Foster & Julieta Cupertino & \\
\hline
\end{tabular}

\begin{tabular}{|l|l|l|l|}
\hline Shadow Line & Tradução & Hemus & $1978 \mathrm{c}$ \\
\hline $\begin{array}{l}\text { A linha de sombra: } \\
\text { uma confissão }\end{array}$ & Maria Antonia van Acker & Revan & 2005 \\
\hline A linha de sombra & Julieta Cupertino & L\&PM & 2010 \\
\hline $\begin{array}{l}\text { A linha de sombra: } \\
\text { uma confissão }\end{array}$ & Guilherme Braga & & \\
\hline
\end{tabular}




\begin{tabular}{|l|l|l|r|}
\hline The Duel & Tradução & Editora & Ano \\
\hline O duelo & Cláudio Figueiredo & Cia. das Letras & 2007 \\
\hline Os duelistas & André de Godoy Vieira & L\&PM & 2007 \\
\hline O duelo & Julieta Cupertino & Revan & 2008 \\
\hline
\end{tabular}

\begin{tabular}{|l|l|l|r|}
\hline Nostromo & \multicolumn{2}{|c}{ Tradução } & \multicolumn{2}{c}{ Editora } & 1983 \\
\hline Nostromo & Donaldson Garschagen & Record & 1991 \\
\hline Nostromo & José Paulo Paes & Cia. das Letras & . \\
\hline
\end{tabular}

\begin{tabular}{|c|c|c|c|}
\hline Almayer's Folly & Tradução & Editora & Ano \\
\hline Perdição & Virgínia Lefèvre & Boa Leitura & 1964 \\
\hline A loucura do Almayer & Julieta Cupertino & Revan & 1999 \\
\hline
\end{tabular}

\begin{tabular}{|l|l|l|r|}
\hline Typhoon & Tradução & Gditora & Ano \\
\hline Tufão & Queiroz Lima & L\&PM & 1936 \\
\hline Tufão & Albino Poli Jr. & 1985 \\
\hline
\end{tabular}

\begin{tabular}{|l|l|l|r|}
\hline Tomorrow & Tradução & Editora & Ano \\
\hline Amanhã & Queiroz Lima & Llobo & 1936 \\
\hline Amanha & Albino Poli Jr. & 1985 \\
\hline
\end{tabular}

\begin{tabular}{|l|l|l|r|}
\hline Karain: A Memoir & Tradução & Editora & Ano \\
\hline Karain, uma lembrança & Virgínia Lefèvre & Boa Leitura & 1964 \\
\hline Karain: uma memória & Julieta Cupertino & Revan & 2004 \\
\hline
\end{tabular}

\begin{tabular}{|l|l|l|r|}
\hline The Brute & \multicolumn{2}{c}{ Tradução } & \multicolumn{2}{c}{ Editora } \\
\hline A fera & Laetitia Vasconcellos & Cia. das Letras & 2005 \\
\hline A bruta & Dirceu Villa & Hedra & 2009 \\
\hline
\end{tabular}

\begin{tabular}{|c|c|c|c|}
\hline Under Western Eyes & Tradução & Editora & Ano \\
\hline Sob os olhos do Ocidente & Marcos Santarrita & Brasiliense & 1984 \\
\hline
\end{tabular}

\begin{tabular}{|l|l|l|r|}
\hline Chance & \multicolumn{2}{c}{ Tradução } & \multicolumn{2}{c}{ Editora } & Ano \\
\hline A força do acaso, ou Chance & Francisco da Rocha Filho & Marco Zero & 1985 \\
\hline
\end{tabular}

\begin{tabular}{|l|l|l|r|}
\hline The Arrow of Gold & Tradução & Editora & Ano \\
\hline A flecha de ouro & Marques Rebelo & Globo & 1940 \\
\hline
\end{tabular}

\begin{tabular}{|l|l|l|r|}
\hline Inside the Tides & \multicolumn{2}{c}{ Tradução } & \multicolumn{2}{c}{ Editora } & Ano \\
\hline Dentro das marés & Julieta Cupertino & Revan & 2004 \\
\hline
\end{tabular}




\begin{tabular}{|l|l|l|r|}
\hline Because of the Dollars & Tradução & \multicolumn{2}{c|}{ Editora } \\
\hline Por causa dos dólares & $\begin{array}{l}\text { Aurélio Buarque de Hollanda } \\
\text { e Paulo Rónai }\end{array}$ & Nova Fronteira & 1978 \\
\hline
\end{tabular}

\begin{tabular}{|l|l|l|r|}
\hline Falk & Tradução & \multicolumn{2}{c}{ Editora } \\
\hline Falk & Queiroz Lima & Globo & 1936 \\
\hline
\end{tabular}

\begin{tabular}{|l|l|l|r|}
\hline The Idiots & Tradução & \multicolumn{3}{c}{ Editora } & Ano \\
\hline Os idiotas & Virgínia Lefèvre & Boa Leitura & 1964 \\
\hline
\end{tabular}

\begin{tabular}{|c|c|c|c|}
\hline The Return & Tradução & Editora & Ano \\
\hline A volta & Virgínia Lefèvre & Boa Leitura & 1964 \\
\hline
\end{tabular}

\begin{tabular}{|c|c|c|c|}
\hline The Lagoon & Tradução & Editora & Ano \\
\hline A laguna & Virgínia Lefèvre & Boa Leitura & 1964 \\
\hline
\end{tabular}

\begin{tabular}{|l|l|l|r|}
\hline The Mirror of the Sea & \multicolumn{2}{|c}{ Tradução } & \multicolumn{2}{c}{ Editora } & 1999 \\
\hline Espelho do mar & Celso Mauro Paciornik & Iluminuras & 1999 \\
\hline
\end{tabular}

\begin{tabular}{|l|l|l|r|}
\hline A Personal Record & Tradução & \multicolumn{2}{c}{ Editora } \\
\hline Um registro pessoal & Celso Mauro Paciornik & Iluminuras & 1999 \\
\hline
\end{tabular}

\begin{tabular}{|c|c|c|c|}
\hline The End of the Tether & Tradução & Editora & Ano \\
\hline O fim das forças & Julieta Cupertino & Revan & 2000 \\
\hline
\end{tabular}

\begin{tabular}{|l|l|l|r|}
\hline Freya of the Seven Islands & Tradução & \multicolumn{2}{c|}{ Editora } \\
\hline Freya das sete ilhas & Julieta Cupertino & Revan & 2003 \\
\hline
\end{tabular}

\begin{tabular}{|c|c|c|c|}
\hline Il Conde & Tradução & Editora & Ano \\
\hline Il conde & Dirceu Villa & Hedra & 2009 \\
\hline
\end{tabular}

\begin{tabular}{|c|c|c|c|}
\hline The Informer & Tradução & Editora & Ano \\
\hline O informante & Dirceu Villa & Hedra & 2009 \\
\hline
\end{tabular}

\begin{tabular}{|c|c|c|c|}
\hline An Anarchist & Tradução & Editora & Ano \\
\hline Um anarquista & Dirceu Villa & Hedra & 2009 \\
\hline
\end{tabular}




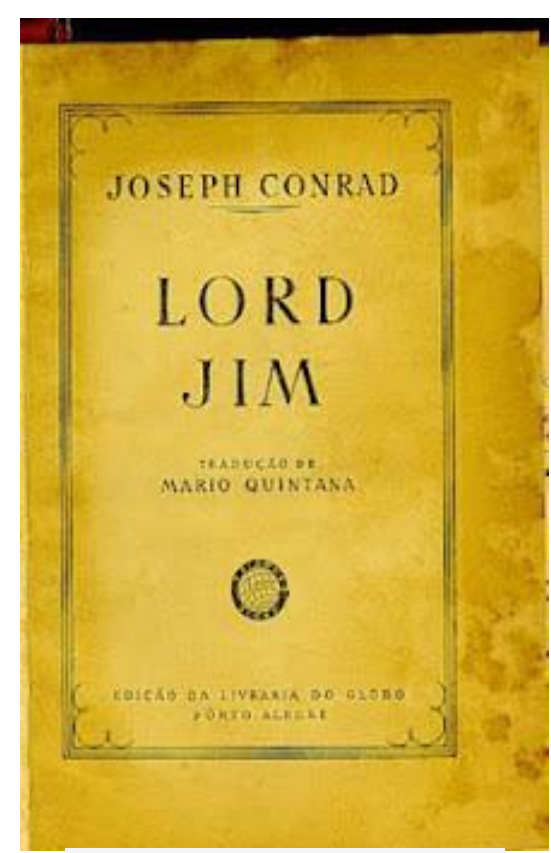

Capa da primeira edição (1939)

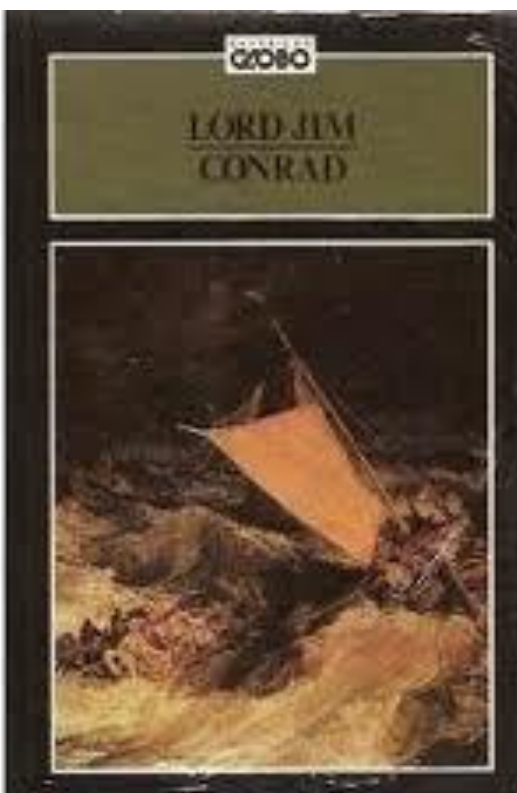

Editora Globo, 1987, para bancas, em papel jornal 


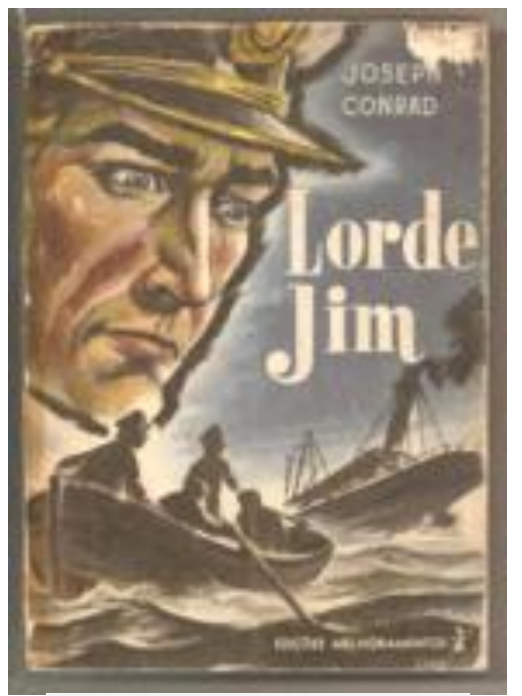

Edições Melhoramentos, 1960

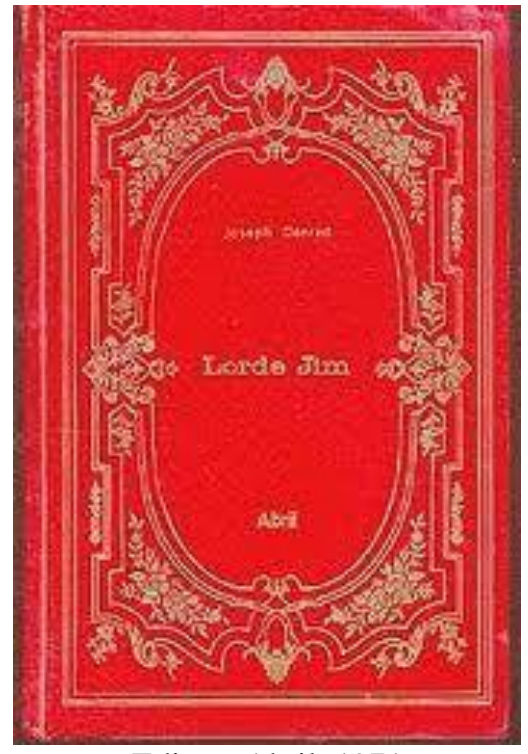

Editora Abril, 1971 


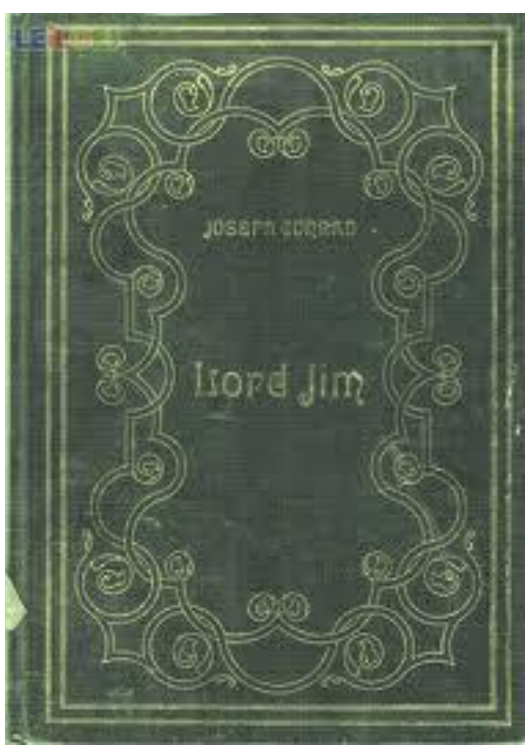

Editora Abril, 1980

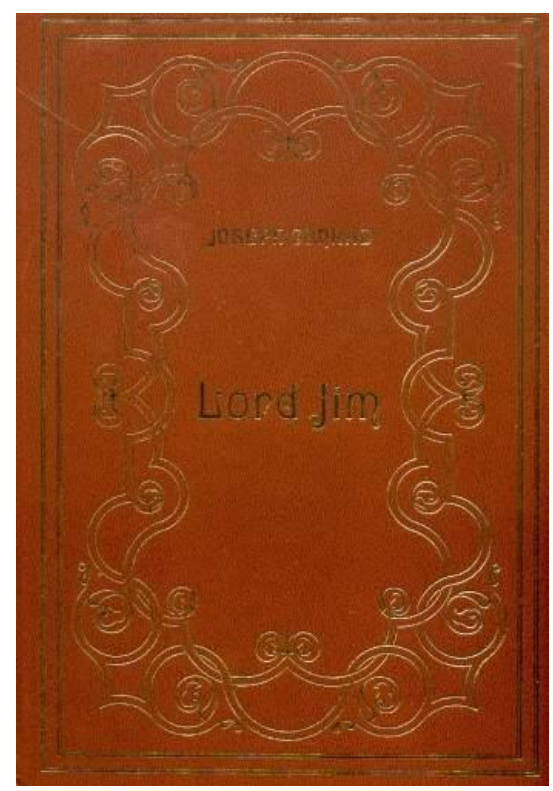

Editora Abril, 1982 


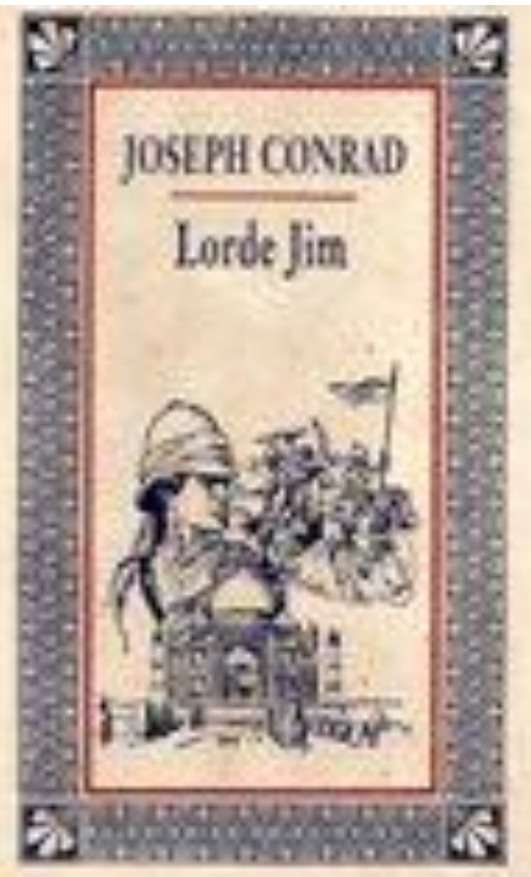

Círculo do livro

274

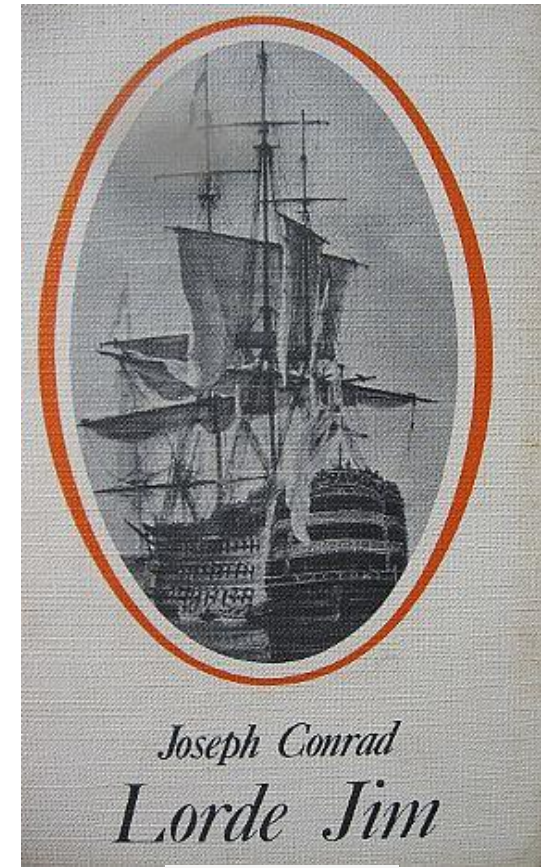

Círculo do Livro 


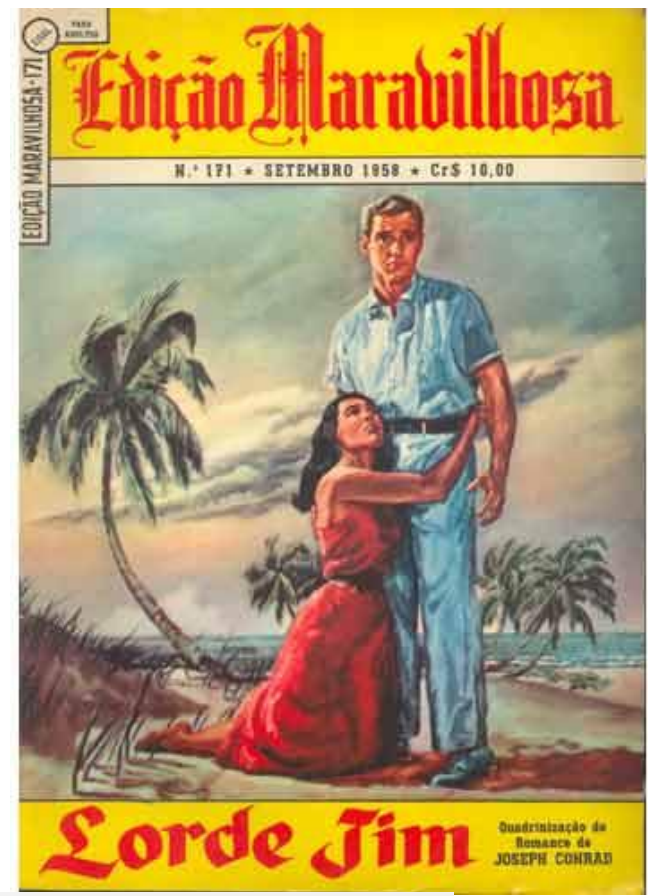

Popularização em quadrinização publicada pela Ebal, Edição Maravilhosa, n. 171, de 1958

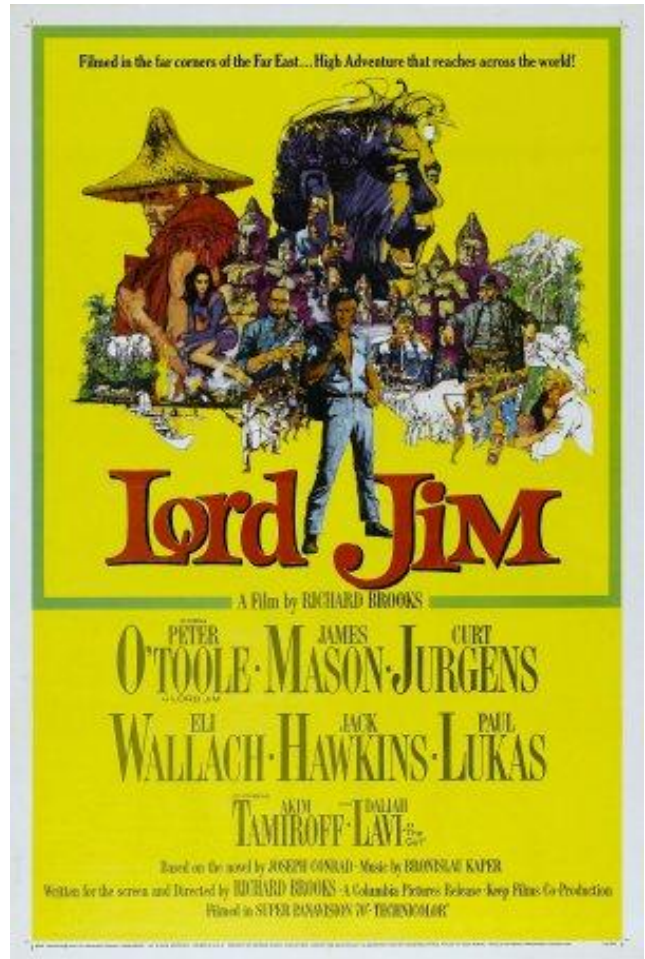

Cartaz do filme realizado em 1965 